\title{
Technology of Critical Thinking Development as Forming Tools for Teacher Professional Competencies in Pandemic
}

\author{
CrossMark

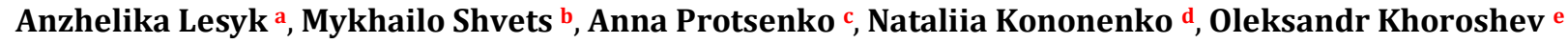 \\ Manuscript submitted: 15 August 2021, Manuscript revised: 18 November 2021, Accepted for publication: 26 December 2021
}

Corresponding Author ${ }^{\text {a }}$

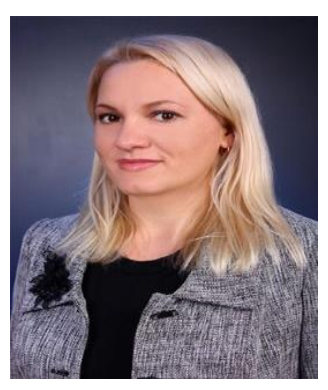

Keywords

education strategy; educational activity; educational program; educational system; global pandemic; higher education; personalization; educational process; professional education;

\begin{abstract}
The article was intended to determine the specifics of the problem of professionalization of the activities of a teacher of vocational training. The object is the professionalization of the teacher's activity. The subject is the problem of professionalizing the activities of a teacher of vocational training. A qualitative analysis of well-known literature sources in the field of technologies for the development of critical thinking in the formation of professional competencies of a higher school teacher in the context of a global pandemic has been carried out. The main methods used in the development of the article were: research methods were used to solve the set tasks: theoretical (study and analysis of scientific and pedagogical, psychological and pedagogical, reference, specialized literature, regulatory documentation on topic of research, additional professional advanced training programs; analysis, comparison, classification of the information received and generalization); empirical during an international pandemic. The following tasks are solved in the article: the concept and specificity of the phenomenon of professionalization of activity; the features of the professionalization of the activity of a teacher of vocational training are characterized; the possibilities of professional competence as a way to solve the problem of professionalization of the teacher's activity are determined.
\end{abstract}

\section{Contents}

Abstract

a Berdiansk state pedagogical university, Berdiansk, Ukraine

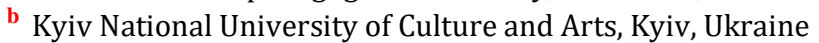

c Kyiv National University of Culture and Arts, Kyiv, Ukraine

d South Ukrainian National Pedagogical University named after K. D. Ushynsky, Odesa, Ukraine

e National University of Civil Defense of Ukraine, Kharkiv, Ukraine 


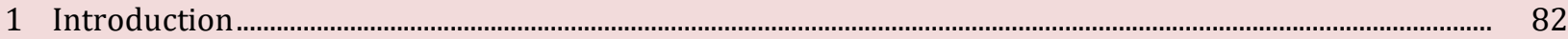

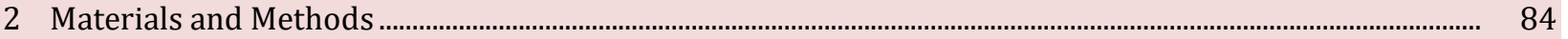

3 Results and Discussions ........................................................................................................................................... 87

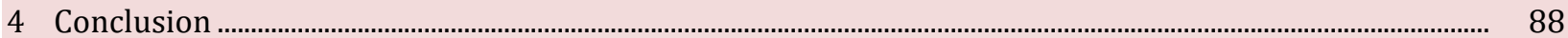

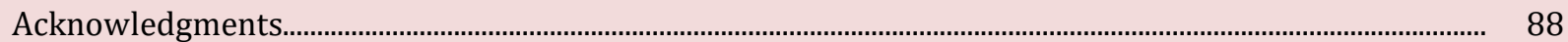

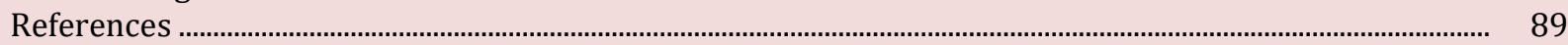

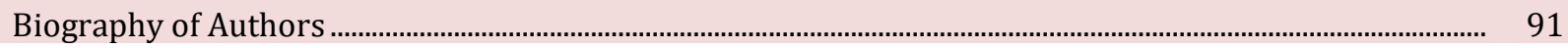

\section{Introduction}

Professionalism and efficiency in any kind of work are manifested twice: in a theoretical-cognitive form, as an image, a project of the desired result, then - as a transformative and creative trend in the social development of mankind. The relevance of research on the problem of human professionalism in any field of activity today is obvious. It is due to the objective features of the development of society at the present stage. One of the most important driving forces of modern social dynamics is becoming professionalism as a complex, multifaceted phenomenon that implies an increase in the social activity of the individual and an increase in the degree of his responsibility both for his destiny and for increasing the efficiency of economic processes in society.

A comprehensive study of professionalism as a social and cultural phenomenon is a prerequisite and a necessary condition for the practical solution of problems directly related to the formation of programs for the development of society and forecasting the processes of its dynamics. Such a study should begin with clarifying the historical context of the problem, identifying the roots of professionalism, the socio-historical prerequisites for the professionalization of labor. The problem of professionalism is one of the oldest in the history of mankind; it has existed in society since the first stages of its development. The foundations for future professionalization were laid from the very first steps of human conscious activity. From the moment of the emergence of a person and his unification into communities for survival, labor has become the main life activity of a person and the main factor in his development. It was the labor activity of a person that became the basis for the formation of professionalism (Clase et al., 2020; Campbell, 2020).

Studies of the role of labor activity in the history of mankind have shown that labor as a general condition for the development of society is difficult to adequately express in the content of one concept, this led to the emergence of numerous definitions of labor as a complex phenomenon unfolding in heterogeneous historical conditions. In the natural sciences, the concept of labor is defined very broadly, starting with its definition as a process of overcoming resistance on a certain path (the product of force over the distance traveled is taken as its measure), and ending with a statement of the relationship between the physical constitution of the body of the worker and the conditions of the workplace. Studies in physiology, medical sciences, and psychology emphasize that any labor activity requires physiological and psychological stress of the participants in the labor process, and also indicate the importance of labor for a person as a living being: with his creative work, a person changes the structure of the world, but at the same time he changes (Tseng et al., 2008; Kwon \& Kim, 2012; Herliah et al., 2022).

The scientific analysis of labor within the framework of humanitarian knowledge was undertaken by K. Marx and F. Engels, who put forward the historical and materialistic understanding of human labor as an essential component of man, in which he manifests himself as a generic being, creating conditions for his material and spiritual existence.

Marx understood labor in both the broad and narrow senses of the word: both as a process of the exchange of matter between man and nature, and as the production of labor tools. However, in both cases, he emphasized the social nature of labor, which is an active relationship of man to nature and, at the same time, the interaction of participants in this process. In general terms, in the works of Marx and Engels, labor is understood as an activity by which a person ensures the exchange of substances with nature, acts concerning nature as a natural force and enters into relationships with other people, develops his essential forces, gives the objects of nature a look that satisfies his needs.

In modern social sciences, human labor activity is considered from different points of view, depending on the goal of the study. In general, there are five different approaches to understanding the labor process that is 
characteristic of modern social thought. Technical and technological - when human labor is considered and defined in the context of man's appropriation of nature, but taking into account his ability to create and rationally use the means of labor. Economic - labor is defined as a conscious, planned human activity to process what is given by nature to meet human needs, as an activity, direct or indirect to ensure the means of subsistence, as "instrumental activity carried out by people to preserve and continue life and aimed at systematic change some properties of the human environment (Corrall, 1998; Susilo et al., 2021).

Philosophical - the starting point of the analysis is the goal and the subject of labor. Labor is defined as any purposeful human activity that is indirectly or directly aimed at creating a certain value (material or spiritual), and as the total human labor contains the labor activity of the "total worker". In the "Philosophical Encyclopedic Dictionary" labor is interpreted as "an expedient activity of a person, in the process of which he, with the help of tools of labor, influences nature and uses it to create objects necessary to satisfy his needs."

Legal - labor is defined as a legal category. This approach is associated with the development of labor relations and the need for legal regulation in the field of labor law. Sociological - expresses the essence of labor as a social phenomenon, points to the specific connections that exist between man and labor, labor and society. Within the framework of modern sociology of labor, labor is defined as "a conscious, universal and organized human activity, the content and nature of which are determined by the degree of development of the means of labor and the characteristics of the social relations within which it is carried out, a person asserts himself in it as a genetic being, creating material and spiritual values. serving the satisfaction of his essential needs.

A modern French sociologist, one of the most prominent representatives of the sociology of labor A. Touraine focuses on the social and axiological meaning of labor. From his point of view, labor is not only a collective activity and the relation of a person to the produced objects. Historically, labor appears as a tool for changing the perception of society about itself, allowing society to be considered as an objective reality, and at the same time as a system of values, norms, and organizational forms. Summing up the analysis of various approaches to the definition of labor, we can conclude that the most common characteristics of human labor activity are the following: professionalization teacher vocational training, human labor is a conscious and purposeful activity, it is a complex activity that is deployed within certain social groups. This is an activity in the process of which certain material and spiritual values $\backslash \mathrm{u} 200 \mathrm{~b} \backslash \mathrm{u} 200 \mathrm{bof}$ social significance are created.

So, even though future professionalization arose even with the intraclan distribution of production and other functions between members of the primitive consanguineous community, the professional differentiation of human labor, or the professional division of labor, arise later, as a result of the social division of labor, with the development of production specialization, in particular, as a result of the separation of animal husbandry from agriculture, and subsequently the emergence of crafts. As a result of the social division of labor, there have been serious changes in the content and structure of the distribution of production functions between members of the community. If in a consanguineous community the distribution of responsibilities between members of the community was carried out taking into account natural inclinations and the intensity of forces and opportunities, then with the division of labor, skills that were inherited were no longer enough to distribute functions between individuals. There was an objective need to prepare people for production activities through special training. It was at this stage of human history that there were grounds to talk about the professionalism of workers, which originated and established itself first in the material and production sphere, and later, with the division of the originally integral human activity into mental and physical labor, became widespread in the spiritual sphere.

Professionalism thus arises with the emergence of professional activity, with its separation from amateur activity, with the professional differentiation of labor activity proper. The professional division of labor as an integral part of the historical process of the social division of labor not only gives rise to the need for coordination and cooperation of professional activities but also leads to changes in the structure of the worker's personality. The main sign of professionalism at an early stage of development of professional activity is a professional skill as the ability to skillfully and creatively fulfill one's professional duties, more generally associated with a conscientious attitude to work in general. The genesis and development of professionalism in society were associated with a change in attitudes towards work in different historical periods.

Various ideas about labor that have existed throughout the history of human society, to a greater or lesser extent, gave an understanding of labor as a social phenomenon, emphasizing both the determining role of a

Lesyk, A., Shvets, M., Protsenko, A., Kononenko, N., \& Khoroshev, O. (2022). Technology of critical thinking

development as forming tools for teacher professional competencies in pandemic. International Journal of Health Sciences, 6(1), 81-91. https://doi.org/10.53730/ijhs.v6n1.3281 
person in the labor process and the importance of labor for society. For a long time in the history of mankind, due to the underdevelopment of tools, labor required great physical exertion. Therefore, as a rule, people considered labor a punishment and sought to avoid it or shift it to others. In modern times, with the development of machine production and the establishment of the norms of the Protestant morality of the capitalist society, the idea of the professional work of a specialist, of the professional vocation of a person as the need for the best mastery of one's profession and the development of professional skills, comes to the fore. But only in the recent history of human society does the idea arise, according to which a person, thanks to professional work, becomes an integral personality, therefore, a professional activity not only positively affects a person but can make him happy.

\section{Materials and Methods}

The educational system accumulates in itself all the processes taking place in society. The more dynamic society develops, the more often problems arise in it, the more often it is necessary to change its social institutions and laws. Society is becoming more educated, and therefore everyone sees its shortcomings better and realizes the need to analyze life situations, continuously remove everything outdated, test innovations, and incorporate them into daily activities. It is no coincidence that the idea of transforming education has been updated all over the world in recent decades, it forms the setting of a new era: to provide a unified educational space and foresee the prospects for its development. The strategic goals of education are formed in line with the concepts of "education", "culture", "competence". Education is understood as a personality quality that characterizes a person's ability to use in his theoretical and practical activities the products of people's material and spiritual labor, based on universal human values and social norms. Culture, being a universal characteristic of activity, sets the program and predetermines the direction of this or that type of activity of the individual, its value typological features, and results. Competence to a greater extent characterizes the results of vocational education and includes both the content of professional (primarily technological) training and the system of non-professional knowledge. From this, we can conclude that education, culture, and competence determine the professionalism of an employee in any field. Therefore, ignoring social needs in education, especially in professional education, is not only inappropriate but to a certain extent dangerous, since it contradicts, first of all, the interests of the individual.

Methodologically, this position is based on the recognition of the dichotomous connection between humanism and sociality, which manifests itself in the fact that humanism does not function outside of society and is already social because it has the property of sociality. Sociality is humanistic because is an objective reflection of culture and allows you to preserve values, pass on traditions, develop the ability to be creative in future generations. In addition, the subject of sociality, its bearer includes not only the state and society but also a person.

Indeed, the modern post-industrial information society imposes certain requirements on its citizens, and therefore it is interested in their possessing certain qualities. Moreover, this does not mean that a personality should be limited only to a given, socially necessary set of qualities, but they should be present in the personality structure as a condition for its successful social functioning.

Thus, the social demand for education is associated with the development of ways to harmoniously combine the interests of both the individual and society when creating educational strategies (Kartashova et al., 2015). In recent years, this issue has become the object of scientific interest of many researchers who reveal its various aspects. This is of particular importance in terms of training teachers of a new generation, especially teachers of vocational training. Indeed, in the preparation of future specialists in the technical field, highly qualified teachers of vocational training are required who can form competencies sufficient for a graduate in the modern labor market. To achieve this goal, teachers and masters are needed who have a high intellectual potential, are competent not only in their discipline but also know other areas, who have modern technologies for working with information, etc.

The professional readiness of a teacher of vocational training should be considered not just as a system of didactic and methodological knowledge and possession of a set of professional and pedagogical skills, but as the development of various abilities, personality traits of a systemic nature, creativity, flexibility, mobility, readiness for innovation, creative attitude to the educational process (Norris et al., 2015). Following these 
requirements, the personnel policy in engineering and pedagogical education is aimed at its humanization and humanitarianization, at the formation of a professional teacher, the creation of creative workshops, pedagogical associations, the constant scientific support of professional training, the widespread introduction of innovative ideas and modern pedagogical experience, a comprehensive nature continuous psychological and pedagogical education and self-education of future teachers of vocational training, for the development of their value attitude to pedagogical skills (Yasechkoet al., 2020; Widana et al., 2021).

An analysis of educational evidence suggests that for the practical training of students, private competencies are allocated to a greater extent, which cannot provide a holistic labor process, requiring teachers of professional training, first of all, the skills of goal-setting, goal-fulfillment, reflection, etc., and the acquired private skills are very disparate and in the aggregate do not cover all aspects of the profession being mastered. Insufficient representation in the learning process of an integrated approach that provides logical and practical relationships between different blocks of training does not allow students to effectively use them in practice. This state of affairs makes it necessary to prepare teachers of vocational training for the implementation of classes and teaching methods aimed at practical acquaintance with holistic professional activities and the acquisition by students of not only elementary but also complex (complex) professional skills that ensure the formation of professional competence of the personality of the future professional, value-motivational orientation in the learning process.

This implies the inseparability of the theoretical and practical aspects of the professional training of teachers of professional education. The relationship of their pedagogical activity and productive work, the optimal combination of educational and transformative principles in their professional activities are the cornerstone of practice-oriented teaching technology at the university (Vallance et al., 2008).

Such cooperation contributes to the restoration and strengthening of ties with enterprises, opens up the following opportunities for educational institutions: easier access to information about the labor market (which specialists and how much to train); accounting for the order of employers on the content of the training of future specialists is ensured; the procedure for adjusting old and developing new training materials and programs are built following the requests of employers; more opportunities are opening up for the organization of industrial practice of students; there are opportunities for organizing short-term internships and advanced training; expanding employment opportunities (Dordick \& Wang, 1993).

Everyday educational practice convincingly proves that the success of the development of the educational sphere as a whole today largely depends on how developed a modern teacher is not only as a professional but also as a person. The orientation of universities and other educational institutions to the search for approaches to the formation of the spiritual and moral personality of a teacher is becoming one of the most important tasks of the modern education system. Features of the educational system that has developed in a particular university determine the options for solving the problems of the formation and development of the personality of a teacher, characteristic of a given university. At the same time, it is possible to single out invariant tendencies common to all higher education institutions in the formation of a teacher's professionalism and the upbringing of high spiritual and moral personal qualities (Van Dinther et al., 2011). Identification of such trends is necessary for their analysis and subsequent adjustment of the orientation of the educational process to achieve the goal of professional development and personal development of a teacher at a university, an advanced training institute, a municipal methodological center (Golitsyna, 2017; Igor et al., 2015). An analysis of the process of formation of the professionalism of a teacher in the system of continuous education (university, postgraduate) revealed the following trends:

- Enrichment of variable educational programs with the content of knowledge about the personality of the teacher based on the ideas of domestic pedagogical culture;

- Expansion of technologies for organizing the educational process;

- The use of information technology in the educational process.

The first trend. It consists of the fact that there is an enrichment of variable educational programs with the content of knowledge about the personality of the teacher based on the ideas of domestic pedagogical culture. "The content of basic pedagogical education is a reflection of the dimensions of a person's being in his activities in nature, society, and culture. The essential characteristic of such a reflection is the integrity of the picture of the world and the person in it, achieved by a complex of psychological and pedagogical, socio-

Lesyk, A., Shvets, M., Protsenko, A., Kononenko, N., \& Khoroshev, O. (2022). Technology of critical thinking development as forming tools for teacher professional competencies in pandemic. International Journal of Health Sciences, 6(1), 81-91. https://doi.org/10.53730/ijhs.v6n1.3281 
humanitarian, cultural, and special disciplines interacting based on philosophical -anthropological methodology. At the same time, pedagogical education acts as a subsystem of society, "inscribed" in the metasystem of culture, which is mastered by the future teacher in the historical and cultural context and modern forms as a naturally organized process (Sarin, 2015).

In the structures of the system of continuous education (higher education institutions, institutes for advanced training of teachers, scientific and methodological centers), the process of development of the spiritual and moral sphere of the personality of a professional teacher is presented depending on the defining value orientations of the teaching staff as a whole and the professional competence in this area of working teachers (Agafonova et al., 2015). Enrichment of the content of education in the curricula, programs of educational institutions of various levels, contributing to the development of the values of the national pedagogical culture, the integration of anthropological, pedagogical, philosophical knowledge and ideas about the personality of the teacher form students' motivation and create a basis for self-education and selfdevelopment. Undoubtedly, such an approach in teacher training is effective, since it has a humane general cultural orientation in the content of education, the foundation of which is the knowledge of domestic pedagogical culture, anthropology, which form conscious ideas about the spiritual, moral, social, and professional values of society (Mishra et al., 2020).

Second trend. It consists of the fact that the technologies for organizing the educational process are expanding. The professionalism of a teacher is determined by his ability to technologically design the educational process to his self-development and the development of students; to technologically investigate and diagnose actual and underdeveloped problems in the development of education, including, with the help of computer tools, to predict its development. Technologies of this type provide for the transformation of the interaction between the teacher and students into personal-equal, subject-activity, individualized relations. Such a transformation is since a teacher-scientist, teacher-practitioner not only teaches but actualizes, stimulates the student for general and professional development, creates conditions for his development, which requires the inclusion of democratic, flexible forms of communication between the teacher and students in the interaction.

The variability of student-centered technologies of education in most educational institutions is obvious today. This is "provided through the following set of psychological and pedagogical conditions: the formation of a personal-creative concept of pedagogical activity; the development of a reflexive and subjective position of the teacher; the inclusion of a teacher in innovative activities; orientation towards a progressive version of personal-creative self-realization; the ascent of individual pedagogical functions (actions, situations) in the system; from typical technologies to personal-creative ones and more". Research activities of teachers in educational institutions, joint activities of teachers from schools, universities, institutes for advanced training, problematic field meetings, specialized seminars, creative competitions, organizational, activity and business games, scientific conferences are traditional forms of work for many institutions that contribute to the selfrealization of teachers in their professional training process (Martyniv et al., 2021). Thus, using a wide range of educational technologies focused on taking into account the personal characteristics of students, the teacher self-affirms in his professional and pedagogical guidelines, social, professional, life values and ideals, the prerequisites for self-education in innovative professional pedagogical activity are formed (Biddiscombe, 1999).

Third trend. It consists of the fact that the use of information technology in the educational process significantly affects the choice of methods, forms, and technologies of pedagogical activity. In recent years, due to the intensive increase in the amount of information in science and practice, the information and communication competence of a teacher has become a necessary condition for the formation of his professionalism. The ability and algorithm of working with information, knowledge, and skills in the use of modern technology, information technology determine the importance of training teachers to use a computer for the accumulation, systematization, transformation of information necessary for the development of education in municipal educational institutions, the possibility of accessing the Internet, the development of a distance learning system (Mason, 2005). 


\section{Results and Discussions}

The ability to work with a computer makes the educational design space extremely wide. The essence of Internet communication is not only correspondence by e-mail, but also participation in conferences, seminars, round tables in online modes. Currently, interactive forms of business communication are developing quite actively: electronic educational portals have been created and are actively developing in the humanities, natural sciences, economics, and legal specialties; the portal of general secondary education; mathematics of all levels of education; health and education and others, electronic libraries function and are constantly updated; thematic pages are created dedicated to topical problems of the development of education on various websites of universities, academies, departments. The use of network information resources, the introduction of distance learning actualizes the process of developing the professional information and communication competence of a teacher (Lytvyn et al., 2021).

The main principles of the functioning of the presented trends in the development of teacher professionalism are the following (Rovai \& Grooms, 2004): the integrity of the content of education, which provides for the consistent familiarization of the teacher with professional values in their unity and integrity. This principle can be implemented only if the philosophical-culturological and pedagogical-professional levels of education serve as its basis in their organic relationship (Iasechko \& Zaitsev, 2021).

The principle of creativity determines the diversity of types and forms of research activities. The implementation of the principle of creativity involves the creation of practice-oriented models, projects, the ability to actively and technologically test new ideas in real pedagogical practice, using, among other things, information technology;

The principle of integration implies a deep penetration of the knowledge of the national pedagogical culture into the content of education in the implementation of their values in the system of continuous education. This is ensured by the inclusion in the content of education of philosophical, scientific, and pedagogical views on the problems of worldview, the place, and purpose of a person in the existing world, the local community, as well as knowledge and skills, to technologically understand these problems, the implementation of modernization processes for the development of education following the requirements of informatization and computerization. this sphere, avoiding the loss of originality and originality of domestic pedagogical traditions (Iasechko et al., 2021).

The revealed tendencies indicate that the process of formation of a teacher's professionalism is multidimensional and can have an appropriate planned orientation in the educational process only if the domestic pedagogical culture, student-centered education technologies, and pedagogical resources of the developing sectors of the global information network are addressed. This requires the organization of targeted training of the teacher for professional and spiritual and moral self-improvement of education) based on the relationship between the ideas of modern and domestic pedagogical culture; acquaintance with the best examples of domestic pedagogical culture, integrating it with the practical possibilities of their real use in modern conditions, taking into account internal motivation for their conscious perception and application of productive-dialogical teaching methods, with the development of ideas for integrating pedagogical, sociocultural (domestic and regional-municipal), methodological knowledge that forms personal responsibility and reflexivity of knowledge and skills in professional self-development; creating conditions for maintaining continuity in the content of education in an educational institution - a higher educational institution - an information and methodological center - an institute for advanced training of educators - an information and methodological center - a municipal educational institution, where the content of training will be related to the previous stage of its preparation and specific problems of professional activities; strengthening the activity approach in the professional development of the teacher's personality, which will be expressed in the personality-oriented nature of interaction with students, productive interaction with science to develop the teacher's professionalism; in the transformation of the interaction between the teacher and the student into a personality-equal, subject-activity, individualized relationship; the formation of information and communication literacy as a necessary and important condition for increasing the effectiveness of education development, which affects not only the procedural side of the organization of the educational process, but also to a certain extent determines the content (actual, operational and targeted),

Lesyk, A., Shvets, M., Protsenko, A., Kononenko, N., \& Khoroshev, O. (2022). Technology of critical thinking

development as forming tools for teacher professional competencies in pandemic. International Journal of Health

Sciences, 6(1), 81-91. https://doi.org/10.53730/ijhs.v6n1.3281 
type (multimedia, graphic, text and etc.) and the effectiveness of the learning process itself (Graham et al., 2013).

\section{Conclusion}

The professionalism of the personality of a teacher, as a complex neoplasm, can be legitimately considered based on the personal principle, which requires the study of psychological functions, processes, states, and activities as directly related to the personality and sufficiently determined by it. Neither activity nor communication in themselves has any mental qualities, and they do not exist by themselves. But these qualities are possessed by a person. Thus, both the problem of communication and the problem of activity are "closed" to the problem of personality.

The conceptuality of the teacher's professional activity and life as a whole is manifested in his ability to organize them based on a single concept, the principle that explains reality in its inconsistency and integrity; implies an internally dialectical approach to objects and phenomena, which means considering them in the unity of mutually penetrating and mutually exclusive opposites. The component of the personal and professional competence of the teacher includes various types of competencies and competencies of the teacher, as well as the readiness of the teacher to implement self-processes.

A person who has reached the optimal level of his professionalism develops such characteristics as the humanistic conceptuality of life, above-standard activity, acmeological readiness for self-realization, the desire for personal and professional achievements, for acme, self-efficacy, creativity. The selected criterion characteristics, determined, on the one hand, by the level of professionalism of the teacher's personality, on the other hand, themselves act as determinants of effectiveness in achieving acme and self-fulfillment.

\section{Acknowledgments}

We are grateful to two anonymous reviewers for their valuable comments on the earlier version of this paper. 


\section{References}

Agafonova, S., Bryukhova, N., \& Kaigorodov, B. (2015). Professional and personal undergraduates' development in the educational process from the perspective of competency-based approach. ProcediaSocial and Behavioral Sciences, 214, 479-486. https://doi.org/10.1016/j.sbspro.2015.11.732

Biddiscombe, R. (1999). Developing the learning support role: some of the challenges ahead. SCONUL Newsletter, 16, 30-34.

Campbell, A. M. (2020). An increasing risk of family violence during the Covid-19 pandemic: Strengthening community collaborations to save lives.Forensic science international: reports, 2, 100089. https://doi.org/10.1016/j.fsir.2020.100089

Clase, C. M., Fu, E. L., Ashur, A., Beale, R. C., Clase, I. A., Dolovich, M. B., ... \& Carrero, J. J. (2020). Forgotten technology in the COVID-19 pandemic. Filtration properties of cloth and cloth masks: a narrative review. In Mayo Clinic Proceedings. Elsevier. https://doi.org/10.1016/j.mayocp.2020.07.020

Corrall, S. (1998). Key skills for students in higher education. SCONuL Newsletter, 15, 25-29.

Dordick, H. S., \& Wang, G. (1993). Information society: A retrospective view. Sage Publications, Inc..

Golitsyna, I. (2017). Educational process in electronic information-educational environment. Procedia-Social and Behavioral Sciences, 237, 939-944. https://doi.org/10.1016/j.sbspro.2017.02.132

Graham, C. R., Woodfield, W., \& Harrison, J. B. (2013). A framework for institutional adoption and implementation of blended learning in higher education. The internet and higher education, 18, 4-14. https://doi.org/10.1016/j.iheduc.2012.09.003

Herliah, A., Baso, Y. S., Hidayanty, H., Syarif, S., Aminuddin, A., \& Bahar, B. (2022). Effect of web-based she smart education models on adolescent girl's knowledge, attitudes, and practice about obesity. International Journal of Health \& Medical Sciences, 5(1), 50-55.

Iasechko, M., Iasechko, S., \& Smyrnova, I. (2021). Aspectos pedagógicos do autodesenvolvimento de alunos de educação a distância na Ucrânia. Laplage Em Revista, 7, 316-323.

Iasechko, M., Shelukhin, O., Maranov, A., Lukianenko, S., Basarab, O., \& Hutchenko, O. (2021). Evaluation of The Use of Inertial Navigation Systems to Improve The Accuracy of Object Navigation. International Journal of Computer Science \& Network Security, 21(3), 71-75.

Iasechko, S., \& Zaitsev, O. (2021). Granting a compulsory license for patent rights in the context of the covid-19 coronavirus pandemic. Pharmacologyonline, 2, 385-397.

Igor, B. A., Nikita, V. M., \& Valeriy, P. B. (2015). Problem methodology as one of the ways of innovative organization of educational process. Procedia-Social and Behavioral Sciences, 166, 227-231. https://doi.org/10.1016/j.sbspro.2014.12.515

Kartashova, A., Shirko, T., Khomenko, I., \& Naumova, L. (2015). Educational activity of national research universities as a basis for integration of science, education and industry in regional research and educational complexes. Procedia-social and behavioral sciences, 214, 619-627. https://doi.org/10.1016/j.sbspro.2015.11.768

Kwon, K., \& Kim, C. (2012). How to design personalization in a context of customer retention: Who personalizes what and to what extent?. Electronic Commerce Research and Applications, 11(2), 101-116. https://doi.org/10.1016/j.elerap.2011.05.002

Lytvyn, V., Akimova, O., Kuznetsova, H., Zenchenko, T., Stepanenko, O., \& Koreneva, I. (2021). The use of synchronous and asynchronous teaching methods in pedagogical education in COVID-19 terms. International Journal of Health Sciences, 5(3), 617-629. https://doi.org/10.53730/ijhs.v5n3.2681

Martyniv, L., Sokolova, A., Kurinna, S., Kopeliuk, O., Sediuk, I., \& Khomova, O. (2021). The modern problems and prospects of music formation and art education development during COVID-19. International Journal of Health Sciences, 5(3), 670-680. https://doi.org/10.53730/ijhs.v5n3.2936

Mason, R. (2005). Globalising education: Trends and applications. Routledge.

Mishra, L., Gupta, T., \& Shree, A. (2020). Online teaching-learning in higher education during lockdown period of COVID-19 pandemic. International Journal of Educational Research Open, 1, 100012. https://doi.org/10.1016/j.ijedro.2020.100012

Norris, E., Shelton, N., Dunsmuir, S., Duke-Williams, O., \& Stamatakis, E. (2015). Physically active lessons as physical activity and educational interventions: a systematic review of methods and results. Preventive medicine, 72, 116-125. https://doi.org/10.1016/j.ypmed.2014.12.027

Lesyk, A., Shvets, M., Protsenko, A., Kononenko, N., \& Khoroshev, O. (2022). Technology of critical thinking development as forming tools for teacher professional competencies in pandemic. International Journal of Health Sciences, 6(1), 81-91. https://doi.org/10.53730/ijhs.v6n1.3281 
Rovai, A. P., \& Grooms, L. D. (2004). The relationship of personality-based learning style preferences and learning among online graduate students. Journal of Computing in Higher Education, 16(1), 30-47.

Sarin, M. N. (2015). Quality education for all? A case study of a New Delhi government school. Policy Futures in Education, 13(3), 360-374.

Susilo, C. B., Jayanto, I., \& Kusumawaty, I. (2021). Understanding digital technology trends in healthcare and preventive strategy. International Journal of Health \& Medical Sciences, 4(3), 347-354.

Tseng, J. C., Chu, H. C., Hwang, G. J., \& Tsai, C. C. (2008). Development of an adaptive learning system with two sources of personalization information. Computers \& Education, 51(2), 776-786. https://doi.org/10.1016/j.compedu.2007.08.002

Vallance, J. K., Taylor, L. M., \& Lavallee, C. (2008). Suitability and readability assessment of educational print resources related to physical activity: Implications and recommendations for practice. Patient education and counseling, 72(2), 342-349. https://doi.org/10.1016/j.pec.2008.03.010

Van Dinther, M., Dochy, F., \& Segers, M. (2011). Factors affecting students' self-efficacy in higher education. Educational research review, 6(2), 95-108. https://doi.org/10.1016/j.edurev.2010.10.003

Widana, I.K., Sumetri, N.W., Sutapa, I.K., Suryasa, W. (2021). Anthropometric measures for better cardiovascular and musculoskeletal health. Computer Applications in Engineering Education, 29(3), 550561. https://doi.org/10.1002/cae.22202

Yasechko, S. V., Iasechko, S., Skomorovskyi, V. B., Andronov, I. V., Zaitsev, O. L., \& Bortnik, O. H. (2020). Features of the Subjective Civil Rights on Patent. 


\section{Biography of Authors}

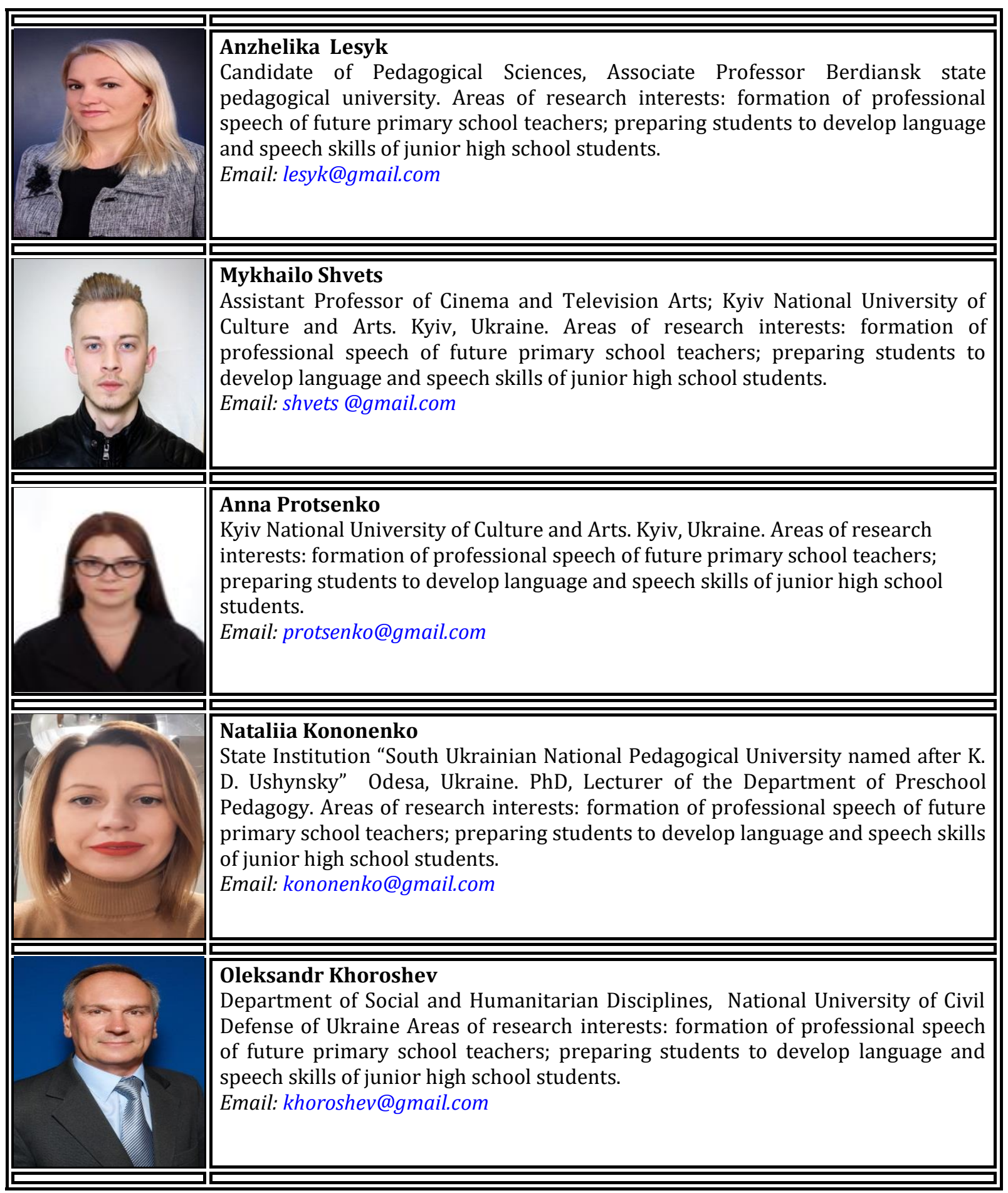

Lesyk, A., Shvets, M., Protsenko, A., Kononenko, N., \& Khoroshev, O. (2022). Technology of critical thinking development as forming tools for teacher professional competencies in pandemic. International Journal of Health Sciences, 6(1), 81-91. https://doi.org/10.53730/ijhs.v6n1.3281 